University of Windsor

Scholarship at UWindsor

Sociology, Anthropology, and Criminology

Department of Sociology, Anthropology and Publications

Criminology

$11-2017$

\title{
"HIV-related syndemic pathways and risk subjectivities among gay and bisexual men: A qualitative investigation
}

\author{
Barry D. Adam \\ University of Windsor
}

Follow this and additional works at: https://scholar.uwindsor.ca/socanthpub

Part of the Gender and Sexuality Commons, Health Psychology Commons, Immune System Diseases Commons, and the Medicine and Health Commons

\section{Recommended Citation}

Barry D Adam, Trevor Hart, Jack Mohr, Todd Coleman, and Julia Vernon. 2017. "HIV-related syndemic pathways and risk subjectivities among gay and bisexual men: A qualitative investigation" Culture, Health and Sexuality 19 (11):1254-1267.

This Article is brought to you for free and open access by the Department of Sociology, Anthropology and Criminology at Scholarship at UWindsor. It has been accepted for inclusion in Sociology, Anthropology, and Criminology Publications by an authorized administrator of Scholarship at UWindsor. For more information, please contact scholarship@uwindsor.ca. 
HIV-related syndemic pathways and risk subjectivities among gay and bisexual men: a qualitative investigation

Barry Adam*a, Trevor Hart ${ }^{b}$, Jack Mohr ${ }^{c}$, Todd Coleman ${ }^{d}$, Julia Vernon ${ }^{b}$

Department of Sociology, Anthropology and Criminology, University of Windsor, Toronto,

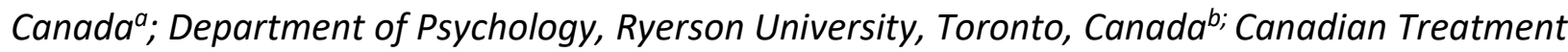
Action Council, Toronto, Canada ${ }^{c}$; Health Sciences, Wilfrid Laurier University, Waterloo, Canada ${ }^{d}$ *Corresponding Author: Barry Adam Email: adam@uwindsor.ca 


\begin{abstract}
Life history interviews were conducted with 40 gay and bisexual men to identify modes of syndemic experience and risk practice. Out of the interview narratives emerged one major and two minor modes of developmental pathways whereby syndemic conditions are navigated and expressed: (1) a combination of adverse childhood events with later episodes of depression and/or substantial substance use, (2) personal disruption that led to periods of depression and anxiety associated with the stresses of migration, and (3) a disorientation and an unravelling of life trajectory in the transition from family of origin to college or work. Risk practices fell into three high-risk modes: active and frequent engagement in condomless sex; unassertive deferment to a partner's initiation of condomless sex; and episodic risk combined with a risk reduction strategy. Three low risk modes were also identified: no recent condomlessness but multiple risk history in interview; a trajectory over time from high to low risk; and consistent low risk practice. These different modes of syndemic experience and risk management may have implications for identification of the effective HIV prevention tools that work best for different sets of men.
\end{abstract}

Keywords: Gay men, HIV, sexual health, sexual subjectivity, Canada 
One of the most fruitful lines of investigation in HIV and LGBT health research in recent years has been inquiry into syndemics, a framework that moves beyond single disease entities and individual behaviour to understand how psycho-social conditions interact to heighten vulnerability to HIV infection and other health issues. Much of this research has been accomplished by applying self-report measures to large samples of gay, bisexual, and other men who have sex with men, then finding strong statistical associations among these indicators, and with risk measures like unprotected anal intercourse or HIV sero-conversion.

To date, much of the syndemics research literature has been devoted to establishing the viability of the concept of syndemics and demonstrating its utility in predicting risk and seroconversion. This study proposes to take the next step in understanding syndemics by examining (a) the degree to which syndemics describe a singular or heterogeneous pathway(s) toward risk, and (b) whether risk among adults affected by syndemics shows distinctive patterns. The policy implications of syndemics research are that HIV prevention could be made more effective by focusing on those most directly affected by the social conditions and psychological outcomes identified as syndemic, and that this subpopulation may benefit for responses tailored to their needs. This study aims to help clarify these implications by identifying modal pathways and risk patterns associated with those most affected by syndemics.

In this study, a set of forty men who reported at least two syndemic indicators were selected from a larger sample of $\mathbf{4 7 0}$ men for life history interviews in order to gain insight into the developmental pathways that underlie both syndemic indicators and the indicators of risk. In this article, we identify some qualitatively distinct major and minor modes of syndemic experience and risk practice to refine syndemics research and contribute to a larger objective of finding ways to lessen vulnerability to health problems.

Building on some twenty years of HIV research that identified a range of antecedents to unprotected anal intercourse and seroconversion, Ron Stall and colleagues $(2003,942)$ drew on Merrill Singer's (1994) notion of 'syndemic' by proposing that "an additive interplay among a set of dangerous psychosocial health conditions is driving the HIV/AIDS epidemic among gay men." By focusing on four indicators that both predict HIV vulnerability and show statistical association with each other, they identified depression, childhood sexual abuse, polydrug use, and partner violence as core psychosocial problems that contribute to the HIV syndemic.

Since this proposition was first advanced, a growing syndemics research literature has repeatedly confirmed the power of these predictors, at times adding other indicators that appear to recur along with these four conditions. Subsequent research has relied most often on depression, childhood abuse, and polydrug use as primary indicators, combining them with one or more measures of: self-esteem, feelings of isolation and loneliness, or sensation seeking (Halkitis et al. 2008b; Vanden Berghe, Nöstlinger, and Laga 2014); sexual compulsivity (Parsons, Grov, and Golub 2012; Pachankis et al. 2015); social anxiety (Hart et al. 2008); childhood bullying, often of a homophobic or racist nature (Díaz, Ayala, and Bein 2004; Mizuno et al. 2012; Herrick et al. 2014); internalised homophobia (Dyer et al. 2012; Pitpitan et al. 2016); migration (Stall, Friedman, and Catania 2007; Egan et al. 2011); and lack of social support (McKechnie, Bavinton, and Zablotska 2013).

Parallel to the syndemic idea in HIV research is a growing health research literature on "adverse childhood events" that has been finding similar relationships between childhood abuse and parental substance use with a variety of health conditions such as "cardiovascular disease, 
lung disease, asthma, arthritis, ulcers and any emotional, nervous, or psychiatric disorders" in general populations (McCrory et al. 2015, 692). Syndemic conditions in HIV, then, may not be unique but rather one face of a larger health syndrome where a small set of interacting social and psychological conditions predispose people to problematic health outcomes.

Much syndemic research has proceeded within a largely psychological framework. These findings are raising additional questions, leading to investigation of the socio-historical contexts (Adam 2016; Siconolfi, Halkitis, and Moeller 2014), circuits and social networks (Adam et al. 2008; Egan et al. 2011), and local cultures (Kurtz 2005; Stall, Friedman, and Catania 2007; Moeller, Halkitis, and Surrence 2011; Aggarwal and Gerrets 2014) that shape syndemic conditions. In addition, phenomenological questions arise concerning the experience of syndemics, the generation of sexual and risk subjectivities, and the personal pathways that lead to vulnerability or resilience in meeting health challenges, and these questions are at the core of this study. A small qualitative research literature (Halkitis et al. 2008a, 2008b; Bruce, Harper, and Adolescent Medicine Trials Network for HIV/AIDS Interventions 2011) opens up these questions, contributing in new ways to the larger objective of "working in tandem with organisations addressing mental health, violence, and substance abuse problems within a community...to increase the efficacy of HIV prevention efforts and related health promotion efforts" (Stall et al. 2003, 943).

We invited a subset of men, who had checked off syndemic indicators on the questionnaire for in the Gay Strengths Study (Hart et al. 2016), for interview to gain insight into their life histories, with particular interest in current risky and risk-avoidant practices. This paper reports specifically on two sets of findings from these interviews: (1) a major and two minor modes of developmental pathways whereby syndemic conditions are navigated and expressed, and (2) three modes of "high risk" and three modes of "low risk" practices that complicate the binary outcome measure of risk as a single instance of condomless sex in the preceding three (or sometimes six) months. These qualitative differences may help refine syndemic analysis, whether quantitative or qualitative, to better understand the mechanisms that lead to variable risk practices and thereby contribute to more tailored and effective methods for HIV prevention.

\section{Methods}

The larger Gay Strengths study recruited 470 gay, bisexual, and other men who have sex with men in the Toronto metropolitan area in Canada. To be eligible for inclusion in the study, participants had to be at least 18, understand English, attend assessment sessions at three times scheduled three months apart, report being HIV-negative at baseline, and have had sexual activity with another man during the six months prior to the initial assessment. They were recruited through posters at community organisations and local businesses, flyers distributed at community events such as the Toronto Pride festival, and advertisements on social media. Particular attention was given to enhancing the diversity of the sample through outreach to Black, South Asian, and East/Southeast Asian communities.

Study participants were screened in a one-hour initial assessment session and provided

written informed consent. They then completed a computer-assisted self-interview questionnaire, which included the following syndemic indicators: 


\section{Depression}

Symptoms of depression were measured using the 20-item Centre for Epidemiologic Studies - Depression scale (CES-D) (Radloff 1977). Participants report on their feelings and behaviour over the past week on a 4-point Likert-type scale ranging from rarely or none of the time (less than 1 day) to most or all of the time (5-7) days. Sample items include "I thought my life had been a failure" and "I felt sad." Participants with a CES-D score of 16 or more screened positive for this syndemic indicator.

\section{History of childhood sexual abuse}

Childhood sexual abuse was measured using the sexual abuse subscale of the Childhood Trauma Questionnaire - Short Form (CTQ-SF) (Bernstein et al. 2003). Participants with a score of 6 or more on the sum of items 20,21, 23, 24, 27 on the CTQ-SF screened positive for this syndemic indicator. A score of 5 indicates that the participant indicated that none of the following occurred during childhood:

1. Someone tried to touch me in a sexual way, or tried to make me touch them.

2. Someone threatened to hurt me or tell lies about me unless I did something sexual with them.

3. Someone tried to make me do sexual things or watch sexual things.

4. Someone molested me.

5. I believe that I was sexually abused.

\section{Multiple substance use}

Used 2 or more substances within the last 3 months, not including tobacco or cannabis: Alcohol use to the point of drunkenness; heroin; methadone; cocaine (including crack); speedball; crystal methamphetamines or "Tina"; ecstasy or " $X$ "; GHB or " $G$ "; other amphetamines, uppers, or speed; ketamine or K; other barbiturates, downers, or sleeping pills; erectile enhancing drugs (e.g., Viagra, Levitra, Cialis)

\section{Homophobic harassment}

If participants reported one or more instances of homophobic harassment before the age of 18 (responding to the question, "BEFORE AGE 18, how many times were you made fun of, picked on, pushed, shoved, hit, or threatened with harm because you were gay/bisexual?"), they screened positive for this syndemic factor.

Once half of the study participants had been enrolled in the larger study, recruitment for the qualitative interviews began by inviting those whose scores indicated three or four syndemic categories, followed by those who scored on at least two syndemic categories, until forty interviews were achieved. Semi-structured interviews explored the life histories of study participants by inquiring into the family, school, work, and neighbourhood relationships in childhood, adolescence, and adulthood as described by Friedman and colleagues (2008). Interviewers were particularly interested in exploring coping strategies to life challenges, sources of stress and social support, and participants' own assessments of adversity and resilience. Interviews were conducted by two of the co-authors (), typically lasted 60-90 minutes, and took 
place in a university office. Interviewees provided written informed consent in accordance with research ethics review by () and received $\$ 30$ to compensate for time and travel to the interview.

Interviews were transcribed and coded to capture a wide range of themes concerning moving into and out of childhood sexual abuse and homophobic harassment, depression, and substance use, along with personal reflections and strategies on pathways through these challenges. All the co-authors read all of the interview transcripts, then narratives were examined to identify the range of views associated with each topic using constant comparative analysis with the assistance of NVivo10 software. Salient themes and excerpts indicative of the range of views were identified iteratively through periodic intensive discussions among the coauthors (Smith, Flowers, and Larkin 2009). This paper focuses on narratives specifically relating to the core defining categories of syndemic psychosocial problems and sexual risk behaviour.

\section{Findings}

\section{Syndemic profile of interview sample}

The types of syndemic indicators represented in the interview sample were as follows:

- 28 indicated having experienced childhood abuse of which 13 indicated sexual abuse, 9 emotional abuse, and 6 more than one form of abuse

- 39 indicated childhood homophobic harassment

- 30 scored greater than 16 for depression (CES-D)

- 18 indicated use of two or more substances in the past 3 months.

The average age of the 40 interviewees was 38 years. Sexual identity was: 34 gay, 2 bisexual, 2 two-spirit, 1 queer, and 1 pansexual. Educational levels were: 3 with high school education, 19 with two years of post-secondary education, 10 with four years, and 8 with post-graduate training. Ethnic origins were: 17 (42.5\%) British, 12 (30\%) other European, 5 (12.5\%) African or Caribbean, 2 Asian (5\%), and 1 each of Latin American, Aboriginal, Middle Eastern, or mixed black and white backgrounds.

\section{Opening syndemic categories}

Previous work employing latent class analysis (Halkitis, Siconolfi \& Solomon 2013) has argued that syndemic problems comprise a single major class. These interviews confirm this major mode typically combining adverse childhood events, such as emotional or sexual abuse or neglect in families of origin, with later episodes of depression and/or substantial substance use, and elevated risk of HIV.

Thirty-three (33) of the 40 interviews in this study appeared to fit that pattern. At the same time, two qualitatively different minor modes emerged from the interviews: (1) personal disruption that led to periods of depression and anxiety associated with the stresses of migration, and (2) a disorientation and unravelling of life trajectory in the transition from family of origin to 
college or work. These two minor modes suggest heterogeneous pathways within the syndemics category.

To give a sense of the narratives of interviewees consistent with the major mode, a number of the syndemic indicators measured by survey take shape in interview as follows:

My childhood basically consisted of moving around.... At school, I was constantly informed by others that I didn't belong. I was very slight, like I was a tiny kid, so I was constantly picked on, and I was beat up more than once.... I remember being at dinner [with family] being like, "I have nothing in common with you people. I don't understand you, any of you," so I was asked to leave and I never returned. That was the beginning of the end. (40s, French ethnicity)

A turbulent home life and extensive experience of school bullying, not only by other students but by teachers and administration in a Catholic school, characterised the life history of another interviewee.

I was very sexually active in high school.... About 18/19 I ended up trying...cooked meth and surprisingly on the first time I landed myself in the hospital and ended up having a near death experience and that was a wakeup call. (20s, British/French)

This same person eventually found his way through years of substance use to a more grounded and tranquil state of being:

It's nice to go to NA [Narcotics Anonymous] and AA [Alcoholics Anonymous] ... and express what's on your mind or what's been bothering you in the past week or day or whatever or just listen to other people talk and it's just this weight off your shoulders.... I find that ever since I've been going to these meetings, I get up in the morning properly, I feel productive, I don't feel judged, and I don't feel like using. It's amazing. (20s, British/European)

A third study participant expressed, as well, a history of challenging conditions both at home and school, later periods of depression, and in this case, successful engagement with psychotherapy.

When I was 11, I was sexually abused by my grandfather, my mother's father so that was traumatic.... My step father was an alcoholic for a couple of years, for I don't know how many years, then he went to $A A$, he stopped.... I think because my birth father left when I was so young, I guess it probably, I think it left voids in my life at times.... High school [was] kind of challenging and then I think because being gay, having feelings for guys, I guess at times maybe I was being a little obvious or people just noticed. There'd be a good-looking guy go by and maybe l'd look and then a couple of the guys would be like, "Oh fag, fag." Thinking, ok this is already difficult being here, now I'm being teased, picked on.... I was hospitalised about 3 years ago. I was feeling--my depression got so bad, I guess I was like feeling suicidal, suicidal thoughts so I've had a psychiatrist since then which I 
see him once a week. He's great, he's gay, been in a relationship with his partner for (25 years. 40s, British)

\section{Migration mode}

Seven of the 40 interviews included substantial migration narratives of arriving in Canada from other countries whether as regular immigrants, refugees, or children in migrating families. Four of these seven migration narratives overlapped with the major mode, but three did not. For these three, migration appeared to be the leading factor related to their reporting of syndemic indicators like depression or substance use. Few if any "adverse childhood events" as defined by the syndemics literature turned up and the life history interview did not reveal the kind of problematic family history that is a prevalent theme in the major mode. Their description of family and school were noticeably more favourable than those in the major mode and their narratives of depression and substance use were also more often temporary and episodic, resolving over time. Interestingly, all three also reported little sexual risk behaviour, while two of the four migrants who reported adverse childhood events did report high sexual risk behaviour. In their own words, the three interviewees in the migration minor mode state,

I grew up in [Islamic country]. I moved to Canada when I was about 14. Life was pretty good, stable, yeah, lots of stability, routines, school was pretty good, one of the better ones in the country. It was pretty normal.... We had a GSA [gay-straight alliance], so it was okay. So you knew people who were against us. So yeah, it was mostly guys in school I dated. I actually dated a guy in school as well. (20s, Middle Eastern)

I was a pretty happy kid I guess. Play, play sports.... I have to say my home and everything was fine. I was raised with my mum and grandma and mostly women in my family. My dad was away but my mum was always there. She gave me like the most, everything she could, she gave it to me at that time.... I always have people hanging out around me. I had a lot of friends. (20s, Latin American)

Much of the stress and depression reported by this individual revolved around arriving in Canada on a student visa, running out of money, and trying to negotiate a lengthy immigration process. The third individual, who was 79 at the time of the interview, reported having been a refugee from World War II Germany, which included a stay in a refugee camp before the age of 10. While certainly an "adverse childhood event," it is not the sort of trauma picked up by conventional childhood abuse measures. In other words, this set of migrants experienced some of the mental health challenges picked up by syndemic measures but followed a somewhat distinct path compared to study participants in the major mode. Migration was both a source of social disruption and stress, but often also its solution, as adjustment to the new and sometimes more supportive social environment in Canada led to a renewed stability in the life course. 


\section{Falling apart in the transition from family to college or workplace}

Four other narratives concern substantial difficulties in finding a way in college or work in late adolescence or early adulthood. While family relationships did involve significant stressors, they were not problematic enough to meet the threshold of 'abuse' and did not occupy a major part of the life history narrative compared to men in the major mode. Rather the primary preoccupation of these narratives is with a current set of dilemmas, dead ends, and a sense of no future in school, career, and personal relationships. In several instances, entry into gay spaces did not result in dating or boyfriends but rather a heightened sense of anxiety and loneliness.

I live with my mum. Actually, she ended up getting divorced and my father then died. Living with her, like I share, like pay towards expenses too.... being a little bit intimidated by people a bit and like I mentioned that, um, just scared to like approach whether it's like for dating or for job or employment for friends and stuff...I'm the type of person too that waits for people to call me and I'm not the one that usually initiates things.... I have depression too; things are heavy... I've had therapy and it hasn't done much. (40s, British/European)

I was required to withdraw twice: academic probation.... I took a year off school.... It was essentially last chance and I flunked out... I went to the doctor, like I was on meds for depression....5 months of crystal. I actually overdosed and was taken to the hospital. I spent the week in a coma (laughter). Almost died and that was where everything changed. (30s, British)

Like the preceding narrative, the following stories contain similar elements: going off to college appears to precipitate a personal crisis associated with doing badly at school, an inability to form new relationships, and a coming out process that did not lead to new social connection or emotional affirmation.

I started to have more anxiety towards things, some more social anxiety. I felt like I was sort of pulling away from my friends more, loneliness, like actual loneliness, started to really come on. I hadn't really known any actual, any other gay people, like I was mostly friends with girls again.... I hadn't known anyone, people weren't coming up to me in gay bars and I didn't have the confidence to go up to people in gays bars so I felt even more lonely cause I felt that I was undesirable.... I ended up breaking down a couple of times in fourth year [of university] and I no longer saw my best friend from second year at that point and yeah and I think that was the year when I started seeing a therapist. It came to, like I was having suicidal thoughts. (20s, British/ European)

My dad I can't talk to. I lived with him up until last year and he's just a very angry person and with my mum there's no trust.... I feel like I came from a period where I was very selfassured to a point where I was just so lost, so alone and isolated and in university having nobody to talk to, but not even necessarily like nobody to even be with by association and have a good time. (20s, British/European) 
These two qualitatively different minor modes, then, merit further exploration to characterise somewhat distinct pathways through the conditions identified by the syndemics concept.

\section{Conceptualising risk practices}

We now turn to study participants' narratives concerning risk practices. The criterion typically employed to identify HIV risk practices is a simple binary between those who report condomless anal sex with a positive or serostatus-unknown male partner in the past six months and those who report no condomless sex." From an inductive, constant comparative analysis of narratives emerged a more nuanced picture of risk practices that fall into the following pattern. "High risk" behaviour sorted into three modes: (1) active and frequent engagement in condomless sex ( $N=4)$, (2) unassertive deferment to a partner's initiation of condomless sex ( $N=2)$, and (3) episodic risk combined with a risk reduction strategy $(\mathrm{N}=7)$. "Low risk" behaviour showed distinctive modes as well: (1) no recent condomlessness but multiple risk history in interview (N=2), (2) a trajectory over time from high to low risk $(\mathrm{N}=4)$, and (3) consistent low risk practice $(\mathrm{N}=21)$. These somewhat distinct modes of risk practice suggest different trajectories for expressing, managing, and living through an HIV risk environment and raise questions concerning how HIV prevention interventions might take account of these varying risk subjectivities to become more effective in engaging the lived realities of different subsets of men.

Active and frequent engagement in condomless sex.

For four study participants, condomless sex was frequent and actively sought. While the full set of reflections and rationales offered by these men for overt barebacking exceeds the parameters of this paper, these narratives make up a modus operandum for navigating sexual environments that are distinguishable from others who meet the measure for high risk sex. For them, condomless sex is actively desired and pursued.

I was out Sunday and (pause) I had more than one guy cum into me. I think I had, I don't know how many sexual partners I had that night. I don't know, I'm actually really surprised, I should have been positive a long time ago, to be quite honest because, I'm sorry, but when I look back at my experience, ninety-nine percent of the time, I don't use condoms. And I have, you know, I'll go out for six, seven hours and I'll have at least twenty, twenty-five partners... Knowing that I'm going to bareback with a bunch of people, and people are ok with it, to me that's like, I'm right in the middle of it. In the middle of it. Which is not, it's so incongruent with who I am, because once I've stepped out of that, it makes no sense. (40s, French)

This next individual, who was classified in one of the minor syndemic modes in the previous section, reported some months of crystal methamphetamine use, including having been previously hospitalised for meth overdose. 
The website that we used and that was reason why I was like, I hope I'm not positive, I went on BBRT [Bareback Real Time] all the time, like all the time. (30s, British)

Another study participant also reported crystal methamphetamine use along with a strong urge for sex without condoms.

I can name innumerable situations where l've looked for random sex and like not used a condom and/or they want to use a condom and I like manage to take it off while they're fucking me, and like they're ok with it because they're fucking me and they love that, and they like shoot and it's like great, but like, there's a, there's like almost a relaxation that happens....when there's no condom that doesn't happen when there is a condom and I top and bottom, and both, never use condoms.... When I put on a condom, I lose my erection, I don't like it at all.... There was a whole period of time when I wanted to seroconvert, and I'd read stories about, and I'd be like totally into because in some ways, my sexual appetite, my sexual behaviour carries with it a lot of guilt, and like a lot of frustration. (Stops to check phone) But I think there's like a lot of guilt associated, guilt and frustration surrounding my sexual preferences. (20s, British)

Finally, this narrative expresses less active engagement and more loss of control related to condomless sex, which appears to have become habitual:

It was this vicious cycle where I was so depressed all week. The weekend comes and I'm like yeah I'm going to have a couple drinks and then do a drug and I didn't want to stop it because it was so much fun. And then it came to a point where I started going to bathhouses here and for a full day of something and then l'd go home and I'm, I'm coming down, I'm so depressed.... Usually when the unsafe intercourse happened it was usually accompanied by when I was under the influence of drugs. That's when I was more brave and didn't care, right? They go hand in hand. (30s, Other European)

Unassertive deferment to partner's initiation.

Unlike the preceding narratives, the stories in this mode are characterised by a rhetoric of unassertiveness. Their narratives are structured to convey the sense of condomless sex happening to these men rather than being actively or consciously sought, nevertheless it occurs repeatedly and without resistance on the part of speaker. Certainly, this is a mode of HIV management that has appeared in other qualitative work on gay men experiencing syndemic conditions (Halkitis et al. 2008a, 9-10) and also recurs in the narratives of men after seroconverting (Adam 2005, 341; Wade Taylor et al. 2013) but has not often been separated out analytically.

I guess all I did was put on trust if I asked the guy if he's clean and he says, yeah, and he was clean then yeah. I'm usually if it's like really in the heat of the moment, if it feels 
really good, my mind will shut off and I don't know why, but I'll just tell the person kind of keep going and stuff. (30s, Caribbean)

It's usually always the other person. To be honest with you, I've never bought a condom in my life, and I don't know, it's not that I have a very relaxed attitude about it--well maybe I do I guess, if I haven't, but I always usually kind of left it up to them. (30s, Aboriginal)

This kind of unassertive location of the self as an object of other men's desires turns up as well among a few of those falling into the low risk category. In this instance, risk is "low" because the narrator reports having only oral sex.

I always had a thing when I first came out at bars that if someone bought me a beer, and I allowed them to buy me a beer, then I would have to go home with them if they wanted, so I was turning down a lot of beers because I was worried and then every now and again I'd accept one and I'd often feel stuck, and I'd sometimes leave the club with someone and just hoping they didn't live far and hoping it could be over soon because I wasn't attracted but I never kind of knew how to get out of the situation. (40s, White)

This set of narratives, while equally high risk according to the usual criteria appear to indicate different subjectivities. While the first set of narratives assert active subjective engagement, the second are characterised by a sense of self as an object within the subjectivity of others.

\section{Episodic risk combined with a risk reduction strategy.}

Unlike the previous two modes where condomless sex is frequent despite HIV risk, here risk reduction is phrased in terms of strategic positioning or condomless sex is characterized as "exceptional" in a larger pattern of condom use. In this instance, the strategy is an active attempt to sero-sort:

I will generally ask if they're negative or undetectable because I know a lot more about sexual health out there. If you're positive and you're not on medication, I will definitely not let you fuck me unsafely but if you are undetectable or you're negative, yes. (20s, British/European)

In another instance, the speaker was interested in safe sex but his boyfriend resisted.

My ex-boyfriend, he, he had a thing against using condoms, and that was actually kind of a problem, like we would fight about that and it's just kind of stupid, actually. But I mean, he wouldn't comply with that, but we only kind of slept with each other at the time, so I kind of just dragged his ass to the clinic, and went, "Ok, if you're not going to do this, then we're all getting our tests done to be sure and what not." So, and yeah, of course, everything's negative. (20s, British/European) 
Various strategies well documented in the research literature, then, like strategic positioning are characteristic of men in this mode. In this case, risky sex was mitigated by seeking out postexposure prophylaxis.

Yes, there were times I did suggest to use it and I mean I will admit probably $90 \%$ of the time I think having anal sex, I've been the top and yeah for me I will admit it feels better without a condom so there are times I'd be like, you're fine, yep you fine yeah, but I know it's a kind of stupid when I think about it.... There was actually one time my ex and I [had] a drunken night and unprotected sex with this guy and it was really actually two guys and it was a really crazy night so we ended up going on what's the HIV medication?

(Interviewer: PEP [post-exposure prophylaxis]?)

Yeah. (40s, British)

These are narratives of inconsistent condom use rather than persistent avoidance.

No condomless sex on survey but multiple risk in interview.

In a few instances, the survey response which indicated no condomless sex in the past six months appeared to be somewhat exceptional against a narrative of inconsistent condom use. The following study participant appears to have strategic positioning in mind as a risk reduction strategy, as well as deferment to a partner.

I'm assuming I'm negative. I don't get tested regularly but I don't get fucked and I don't have any indication that I've got any kind of you know. (I: Do you tend to go along with your partner's wishes or? Regarding safe sex or?) Oh absolutely. Oh, if they want it I'm not going to try and dissuade them. That would be really-- (I: What if they don't?) Then I honour as well. It's their ass so I figure that's how you want it, you want it. (50s, European)

The following narrator, who migrated from his home country with a partner, says that he has slowed down in terms of risk taking and reports nothing recently, nevertheless,

(Interviewer: So, with the sex outside of the main relationship are you ever thinking about HIV and STIs or like, does that come up?)

I'm paranoid, immensely paranoid but I don't do anything about it.

(Interviewer: So, it doesn't change the type of sex you're having at all?) 
No and it's very irresponsible I know. I prefer to be in live in the bliss of not knowing. (40s, White)

\section{Trajectory from high to low risk.}

In four intriguing cases, interviewees speak of transitioning from a lengthy period of condomless sex to safer methods of risk management. All of these men were somewhat older and looked back on their youth as a "wilder" time. Two of the four reported having done sex work episodically in their youth. One went on to see a psychiatrist for a decade to be treated for depression and now reports "almost always" using condoms. The other went on to work in an AIDS service organisation, then experienced a severe health scare that led to more a cautious approach. A third man eventually sought counselling, was treated for alcoholism, and went on to get an masters degree in psychology. The fourth characterised his youth as "promiscuous" followed by a now lengthy relationship with a partner he has married and with whom he is contented to remain monogamous. In his own words,

[At] 25, I got a partner and we've been together ever since, so, yeah. So up until, between 20 and 25, I must say I was promiscuous and I generally didn't use any protection.... Now that I look back, it was actually incredibly reckless, and a couple of those boyfriends I had, guys I went around with at that time, have passed away from AIDS. (40s, British)

While very different life trajectories, all describe a lengthy maturation process that meant less risk taking over time.

\section{Consistent low risk practice}

Finally, it is worth noting that two-thirds of the interviewees $(N=21)$ did not report recent receptive condomless sex with a positive or serostatus unknown partner, despite syndemic indicators, for a number of reasons ranging from consistent condom use to having a husband or regular boyfriend who was HIV-negative, having few recent partners, or preference for nonpenetrative sex. Included in this group are two men with recent histories of overdose or "hitting rock bottom" who went into intensive substance use therapy. They had both stopped having sex in recent months and it was unclear if they had a plan for lasting risk reduction.

\section{Conclusion}

Life history interviews with gay and bisexual men affected by syndemic indicators reveal qualitative differences in life experiences, crisis points, and risk outcomes. While the current research literature on those affected by syndemics tends to subsume life trajectories and risk subjectivities into a single large category, these interviews point to two minor modes characterised by migration stress, which tended to resolve over time, or trouble transitioning from home to college or work which led to a strong sense of defeat. High and low risk modes of 
HIV management in sexual practices also fell into qualitatively distinct types that might be considered different forms of sexual subjectivity, ranging from active and frequent pursuit of condomless sex, to deferment to the initiative of others, or a combination of risk reduction strategies.

Like the existing syndemics research literature, this study found HIV risk behaviour to be elevated among those with syndemic indicators compared with the larger sample of gay men, nevertheless about half of them currently showed low risk practices. Interviews also revealed that for some men, recent low risk behaviour was apparently exceptional in a larger pattern of high-risk practice. These different modes of syndemic experience and risk management may have implications for the identification of the effective HIV prevention tools that work best for different sets of men. Interventions tailored to these different modes of experience may prove more effective than those aimed at individuals who are simply members of a "risk population." Different kinds of solutions may be appropriate, for example, for men in the two minor modes of syndemic experience compared to the life histories that fell into the major mode: institutional support for LGBT migrants on the one hand and institutional support for LGBT students and other young people finding their way from home to new environments may contribute to resilience (e.g. Project PRIDE (Smith et al. 2016)). It will be worth exploring, as well, if these kinds of differences affect uptake of biomedical or psychotherapeutic prevention methods like PrEP or behavioural therapy.

This profile of syndemic pathways and risk subjectivities is likely influenced by the sociohistorical environment from which study participants were drawn, and may not look the same in other locations. All lived in a major metropolitan area in a country with a relatively liberal legal structure (anti-discrimination laws with respect to sexual orientation, same-sex marriage) that could shape "minority stress" and opportunities to live as gay or bisexual men. Migration mode may also be particularly salient in this location where approximately half of city residents are foreign-born. Future directions for research could include further exploration of heterogeneity among men with syndemic indicators, and the detection of major and minor modes in locations with different socio-political environments or demographic make-up, or they could focus on other kinds of higher risk samples such as men with many recent sexual partners, injection drug users, or ethnic minority communities. Overall, the investigation of syndemics has proven fruitful in identifying psychosocial conditions associated with higher risk outcomes. Further differentiation of the life trajectories and pathways through these conditions and the risk subjectivities associated with them has the potential to better identify the kinds of supports that could lead to improved health outcomes.

\section{Acknowledgements}

We would like to thank the other members of the Gay Strengths research team: David J Brennan, Syed Noor, Sandra Gardner, Winston Husbands and Ted Myers for their assistance. We would also like to thank the volunteer research assistants of the HIV Prevention Lab for transcribing the interviews, including Aidan Ablona, who also contributed to the coding of interviews. This research was funded by the Canadian Institutes for Health Research. 



\section{References}

Adam, Barry D. 2005. "Constructing the Neoliberal Sexual Actor." Culture, Health \& Sexuality 7 (4): $333-$ 346.

Adam, Barry D. 2016. "Neoliberalism, Masculinity, and HIV Risk." Sexuality Research \& Social Policy 13 (4): 321-329.

Adam, Barry D, Winston Husbands, James Murray, and John Maxwell. 2008. "Circuits, Networks, and HIV Risk Management." AIDS Education and Prevention 20 (5): 420-435.

Aggarwal, Sanjay, and Rene Gerrets. 2014. "Exploring a Dutch Paradox." Culture, Health \& Sexuality 16 (2): 105-119.

Bernstein, David, Judith Stein, Michael Newcomb, Edward Walker, David Pogge, Taruna Ahluvalia, John Stokes, et al. 2003. "Development and Validation of a Brief Screening Version of the Childhood Trauma Questionnaire." Child Abuse \& Neglect 27: 169-190.

Bruce, Douglas, Gary Harper, and Adolescent Medicine Trials Network for HIV/AIDS Interventions. 2011. "Operating without a Safety Net." Health Education and Behavior 38 (4): 367-378.

Díaz, Rafael, George Ayala, and Edward Bein. 2004. "Sexual Risk as an Outcome of Social Oppression." Cultural Diversity and Ethnic Minority Psychology 10 (3): 255-267.

Dyer, Typhanye, Steve Shoptaw, Thomas Guadamuz, Michael Plankey, Uyen Kao, David Ostrow, Joan Chmiel, Amy Herrick, and Ron Stall. 2012. "Application of Syndemic Theory to Black Men Who Have Sex with Men in the Multicenter AIDS Cohort Study." Journal of Urban Health 89 (4): 697708.

Egan, James, Victoria Frye, Steven Kurtz, Carl Latkin, Minxing Chen, Karin Tobin, Cui Yang, and Beryl Koblin. 2011. "Migration, Neighborhoods, and Networks." AIDS \& Behavior 15: S35-S50.

Friedman, Samuel, Pedro Mateu-Gelabert, Milagros Sandoval, Holly Hagan, and Don Des Jarlais. 2008. "Positive Deviance Control-Case Life History." BMC Public Health 8: 94.

Halkitis, Perry, Daniel Siconolfi, Megan Fumerton, and Kristin Barlup. 2008a. "Facilitators of Barebacking among Emergent Adult Gay and Bisexual Men." Journal of LGBT Health Research 4 (1): 11-26.

Halkitis, Perry, Daniel Siconolfi, Megan Fumerton, and Kristin Barlup. 2008b. "Risk Bases in Childhood and Adolescence among HIV-Negative Young Adult Gay and Bisexual Male Barebackers." Journal of Gay and Lesbian Social Services 20 (4): 288-314.

Hart, Trevor, Carolyn James, David Purcell, and Eugene Farber. 2008. "Social Anxiety and HIV Transmission Risk among HIV-Seropositive Male Patients." AIDS Patient Care and STDs 22 (11): 879-886.

Hart, Trevor, Syed Noor, Barry D Adam, David Brennan, Sandra Gardner, Winston Husbands, Ted Myers, and Jessica Cattaneo. 2016. Number of Psycho-Social Strengths Predicts Reduced HIV Sexual Risk Behaviours above and Beyond Syndemic Problems among Gay and Bisexual Men. Paper presented at the 25th Annual Canadian Conference on HIV/AIDS Research, Winnipeg, April.

Herrick, Amy, Ron Stall, James Egan, Sheree Schrager, and Michele Kipke. 2014. "Pathways Towards Risk." Journal of Urban Health 91 (5): 969-982.

Kurtz, Steven. 2005. "Post-Circuit Blues." AIDS \& Behavior 9 (1): 63-72.

McCrory, Cathal, Cara Dooley, Richard Layte, and Rose Anne Kenny. 2015. "The Lasting Legacy of Childhood Adversity for Disease Risk in Later Life." Health Psychology 34 (7): 687-696.

McKechnie, Michelle, Benjamin Bavinton, and Iryna Zablotska. 2013. "Understanding of Norms Regarding Sexual Practices among Gay Men." AIDS \& Behavior 17: 1245-1254.

Mizuno, Yuko, Craig Borkowf, Gregorio Millett, Trista Bingham, George Ayala, and Ann Stueve. 2012. "Homophobia and Racism Experienced by Latino Men Who Have Sex with Men in the United States." AIDS \& Behavior 16: 724-735. 
Moeller, Robert, Perry Halkitis, and Katie Surrence. 2011. "The Interplay of Syndemic Production and Serosorting in Drug-Using Gay and Bisexual Men." Journal of Gay \& Lesbian Social Services 23: 89106.

Pachankis, John, H Jonathon Rendina, Arjee Restar, Ana Ventuneac, Christian Grov, and Jeffrey Parsons. 2015. "A Minority Stress--Emotion Regulation Model of Sexual Compulsivity among Highly Sexually Active Gay and Bisexual Men." Health Psychology 34 (8): 829-840.

Parsons, Jeffrey, Christian Grov, and Sarit Golub. 2012. "Sexual Compulsivity, Co-Occuring Psychosocial Health Problems, and HIV Risk among Gay and Bisexual Men." American Journal of Public Health 102: 156-162.

Pitpitan, Eileen, Laramie Smith, David Goodman-Meza, Karla Torres, Shirley Semple, Steffanie Strathdee, and Thomas Patterson. 2016. "'Outness' as a Moderator of the Association between Syndemic Conditions and HIV Risk." AIDS \& Behavior 20: 431-438.

Radloff, LS. 1977. "The CES-D Scale: A Self-Report Depression Scale for Research in the General Population." Applied Psychological Measurement 1: 385-401.

Siconolfi, Daniel, Perry Halkitis, and Robert Moeller. 2014. "Homo Economicus." Critical Public Health 25 (5): 554-568.

Singer, Merrill. 1994. "AIDS and the Health Crisis of the US Urban Poor." Social Science \& Medicine 39 (7): 931-948.

Smith, Jonathan, Paul Flowers, and Michael Larkin. 2009. Interpretative Phenomenological Analysis. London: SAGE.

Smith, Nathan, Trevor Hart, Chérie Moody, Amy Willis, Marie Faaborg Andersen, Martin Blais, and Barry D Adam. 2016. "Project Pride: A Cognitive-Behavioral Group Intervention to Reduce HIV Risk Behaviors among HIV-Negative Young Gay and Bisexual Men." Cognitive and Behavioral Practice 23 (3): 398-411.

Stall, Ron, MS Friedman, and J Catania. 2007. "Interacting Epidemics and Gay Men's Health." In Unequal Opportunity, edited by Richard Wolitski, Ron Stall and Ronald Valdiserri, 251-274. Oxford: Oxford University Press.

Stall, Ron, Thomas Mills, John Williamson, Trevor Hart, Greg Greenwood, Jay Paul, Lance Pollack, Diane Binson, Dennis Osmond, and Joseph Catania. 2003. "Association of Co-Occurring Psychosocial Health Problems and Increased Vulnerability to HIV/AIDS among Urban Men Who Have Sex with Men." American Journal of Public Health 93 (6): 939-942.

Vanden Berghe, Wim, Christiana Nöstlinger, and Marie Laga. 2014. "Syndemic and Other Risk Factors for Unprotected Anal Intercourse among an Online Sample of Belgian HIV Negative Men Who Have Sex with Men." AIDS \& Behavior 18: 50-58.

Wade Taylor, S, Conall O'Cleirigh, Kenneth Mayer, and Steven Safren. 2013. "HIV-Infected Men Who Have Sex with Men Who Engage in Very High Levels of Transmission Risk Behaviors." Psychology, Health \& Medicine 18 (5): 576-587.

Wilton, James, Taylor Kain, Shawn Fowler, Trevor Hart, Troy Grennan, John Maxwell, and Darrell Tan. 2016. "Use of an HIV-Risk Screening Tool to Identify Optimal Candidates for PrEP Scale-up among Men Who Have Sex with Men in Toronto, Canada." Journal of the International AIDS Society 19. doi: http://dx.doi.org/10.7448/IAS.19.1.20777.

\section{Footnotes}


'The Gay Strengths study was a survey of gay, bisexual, and other men who have sex with men to identify protective factors and resilience leading to health outcomes.

ii At the time of this study, Truvada had not yet been approved as a pre-exposure prophylaxis in Canada and its use was still rare (Wilton et al. 2016) 